\section{Treating patients with postoperative stress urinary incontinence}

To the Editor: Allow me to preface my remarks with a speculation that I am the only member of the CUA whose practice has been severely hampered due to the destruction from Hurricane Ike. (I joined the faculty of the University of Texas Medical Branch in Galveston, Tex, just before the storm.) In any case, I enjoyed the articles concerning the treatment of male stress urinary incontinence postprostatectomy published in a recent issue of $C U A J .^{1,2}$ I think we can learn much from the experience with female urology and slings. Before the development of relatively loose suburethral Prolene slings, sling surgery was fraught with problems, including the adjustment of sling tension. The Burch, Marshall-Marchetti and bladder neck suspensions have problems as well, with the Burch suspension being accepted as the gold standard. The main problem with the new slings was mainly adjusting the tension, but the results have basically been good. In addition, it is possible to visualize the sling postoperatively for any problems, for example, with looseness.

Translating this to male patients, slings are primarily for poor support, although slings can work for intrinsic sphincter deficiency. However, we don't currently have the tools to identify poor support. We need assistance from our imaging colleagues in the same way we can now image female pelvic floor prolapse and dysfunction. The problem isn't large volume loss versus less volume loss, so much as understanding the mechanism of incontinence. Theoretically, poor support should respond to a relatively loose sling (without bone anchors.) We don't know without adequate studies if slings or the artificial urinary sphincter (AUS) are better for postprostatectomy incontinence related to a neurovascular etiology.

But, to add to the controversy, I have an anecdotal case with a very short follow-up to emphasize our lack of knowledge. The patient was a senior citizen whose only sequalae from a stroke 20 years ago had been total urinary incontinence. He had an unremarkable prostate and prostatespecific antigen level, and no response to medications or conservative management such as pelvic exercises. After placement of a loose nonanchored sling sub-bulbous urethra, the patient was totally dry for 2 months. (The catheter was removed $24 \mathrm{hr}$ after the operation.)

I encourage more research and scientific study for better results for our patients, but I suspect the AUS will go the way of the Marshall-Marchetti because sustained constriction of the urethra is unphysiological. Furthermore, as patients age and move, they can end up in communities with physicians lacking the skills to deal with AUS problems.

\section{Jerry Frankel, MD, FACS}

Division of Urology, University of Texas Medical Branch, Galveston, Tex.

Competing interests: None declared.

\section{References}

1. Carlson KV. Suburethral slings for postprostatectomy stress urinary incontinence. Can Urol Assoc J 2008;2:532-5.

2. Herschorn $\mathrm{S}$. The artificial urinary sphincter is the treatment of choice for postradical prostatectomy incontinence. Can Urol Assoc J 2008;2:536-9.

CUAJ is read by at least 3000 urologists and related specialists in Canada and around the world.

If you want to reach urologists, there is no better place for your classified advertisement. Please contact the journal at journal@cua.org or call 514 395-0376 x40 for a price list, specifications and deadlines. 